\title{
AsESORÍA CIENTÍFICA Y POLÍTICA PÚBLICA: LA GESTIÓN DE LA PANDEMIA EN GUATEMALA
}

\author{
Luis Guillermo Velásquez Pérez ${ }^{1}$ \\ lgvelasq@gmail.com \\ Universidad de San Carlos de Guatemala
}

\begin{abstract}
Este artículo analiza la influencia de la asesoría científica en la gestión de la pandemia en Guatemala a través de una serie de valoraciones respecto al diseño y los alcances de la política sanitaria y laboral que fueron implementadas entre marzo y noviembre de 2020, así como de los actores que intervinieron durante el proceso. Para lograrlo se dividió en tres partes: antecedentes, análisis de la asesoría científica y conclusiones. En la primera se realiza una revisión general del estado de la ciencia y tecnología en Guatemala y una descripción de la reacción pronta del gobierno central ante el primer caso de Covid-19. En la segunda se discute y reflexiona en torno a la incidencia real de la asesoría científica, especialmente, la proveniente de Coprecovid en la formulación de las políticas mencionadas; $y$, finalmente, en la tercera se plantean las conclusiones generales respecto al papel de los actores que más incidieron en la gestión de la pandemia.
\end{abstract}

Palabras clave: asesoría científica, política pública, covid-19 y gobierno.

\section{SCIENTIFIC ADVICE AND PUBLIC POLICY: THE MANAGEMENT OF THE PANDEMIC IN GUATEMALA}

This article analyzes the influence of scientific advice on the management of the pandemic in Guatemala through a series of evaluations regarding the design and implementation of the health and labor policy that were implemented between March and November 2020, as well as the actors who intervened during the process. To achieve this, this article is divided into three parts: the background, the analysis of the scientific advice and the conclusions. The first includes a general review of the state of science and technology in Guatemala and a description of the prompt reaction of the central government to the appearance of the first case of Covid-19. The second discusses and reflects on the real impact of scientific advice, especially that from Coprecovid in the formulation of the aforementioned policies; and, finally, in the third part, the general conclusions regarding the role of the actors that most affected the management of the pandemic are raised.

Keywords: scientific advice, public policy, covid-19 and government.

\footnotetext{
1 Politólogo, maestrando en estadística aplicada y profesor universitario interino
} 


\section{Antecedentes}

\subsection{El estado de la ciencia y tecnología en Guatemala}

La aparición de la pandemia en el mundo puso de relieve la importancia de lo público y de los sistemas de salud y seguridad social, así como de la necesidad de institucionalizar programas en investigación y desarrollo y de expandir la inversión en ciencia y tecnología (CyT). En Guatemala reafirmó la existencia de una serie de deficiencias estructurales en materia de protección social y servicios públicos, de problemas sociales como la pobreza multidimensional que alcanza al 61.1\% de la población y las desigualdades que se acrecientan según la procedencia social y territorial, que forman parte de un conjunto de expresiones de lo que se ha denominado captura del Estado. Pero también de las debilidades institucionales en la recolección y generación de datos y de la falta de preparación para atender, gestionar y responder emergencias desde los datos y la evidencia científica.

Dos breves ejemplos de lo anterior pueden observarse en el limitado papel que desarrollaron el Instituto Nacional de Estadística (INE) y la Secretaría Nacional de Ciencia y Tecnología (SENACYT) durante la pandemia en 2020, cuyas naturalezas para las que fueron creadas pudieron haber aportado para que su gestión fuese ordenada, estratégica y eficiente. El INE, rector del Sistema Estadístico Nacional, era necesario para medir el impacto del Covid-19 en las empresas, en la educación, el mercado laboral y en elementos demográficos relevantes, por dar algunos ejemplos.

Por su parte la SENACYT, la institución gubernamental creada en 1992 que funciona bajo la dependencia de la Vicepresidencia de la República y ejecuta las decisiones del Consejo Nacional de Ciencia y Tecnología (CONCYT), pudo haber tenido mayor actividad en el apoyo al desarrollo de plataformas para registrar a los beneficiarios de los programas de ayuda económica que fueron aprobados por el Congreso de la República, acelerar acuerdos previos relativos al gobierno electrónico, así como el involucramiento de las Comisiones Técnicas y científicos asociados del Sistema Nacional de Ciencia y Tecnología (SINCYT) para mejorar el circuito de toma de decisiones, en el caso que ocupa este artículo, a las relacionadas a la política sanitaria y la política laboral.

Los antecedentes de ambas instituciones son un buen punto de partida para comprender las circunstancias que rodearon la limitación de su papel en la gestión de una emergencia de las dimensiones del Covid-19 cuando precisamente eran dos actores clave en la generación de datos y evidencia científica. En ese orden de ideas, una radiografía general nos permite observar que, de entrada, el INE no contempla siquiera la realización de encuestas sobre ciencia y tecnología como lo hacen los institutos de estadística mexicano y costarricense sobre tecnologías de información y comunicación, así como de otros temas relacionados a CyT. Pero más que una decisión administrativa, es una cuestión de posibilidades institucionales debido 
al diseño legal del instituto y a los recursos humanos y económicos con los que cuenta para obtener los instrumentos de medición e implementar las metodologías adecuadas. Recién en 2018 pudo realizar el primer censo en 16 años y en 2019 recibió 79 millones de quetzales de presupuesto anual, el $0.09 \%$ del presupuesto total de la nación para ese año, del cual únicamente el 19.76\% estaba destinado a la generación de censos y encuestas.

En cuanto a la SENACYT, la Secretaría se ha limitado a ser un órgano articulador con dificultades para mantener la coherencia científica en el proceso de desarrollo de las iniciativas que han impulsado (Chang, 2020). Si bien durante la última década ha tomado una mayor notoriedad y regularidad respecto a la atención que ha recibido por parte de organismos públicos y privados, no se ha visto reflejado en su presupuesto anual, ya que durante los últimos tres años ha rondado entre 30 y 32 millones de quetzales. Una cantidad similar al presupuesto que recibe la Seguridad Perimetral al Binomio Presidencial ${ }^{2}$, una institución de menor orden y cuyos aportes son pocos significativos para el desarrollo. Además, es claramente insuficiente si el presupuesto para la SENACYT se compara respecto al Producto Interno Bruto (PIB) o al presupuesto del Ministerio de Defensa Nacional que es hasta 70 veces mayor.

No obstante, el estudio de la UNESCO sobre el Relevamiento de la Investigación y la Innovación en la República de Guatemala es el que traza de una manera más amplia y detallada el estado de la ciencia y tecnología en el país. En dicho estudio, la UNESCO (2017) destaca que si bien SINCYT ${ }^{3}$ reúne las características mínimas de todo Sistema Nacional de Innovación, enfrenta una serie de factores que dificultan el desarrollo científico y tecnológico: el número de científicos es 16 veces más pequeño que el promedio en América Latina; la investigación y la innovación no se refleja visiblemente en la economía nacional debido a que tiene un déficit entre 973 y 1,173 investigadores/as de jornada completa por millón de habitantes; la inversión pública en educación superior es de un tercio respecto al promedio en América Latina a pesar del crecimiento exponencial del número de estudiantes universitarios y el número de publicaciones científicas anuales la hace ocupar el puesto 16 en producción científica en la región.

La UNESCO (2017) también destaca la ausencia de estudio y difusión respecto a la variedad de etnomedicinas mayas que existen, han sido analizados por otros estudios internacionales y son utilizables para tratamientos médicos modernos en los cuales residen oportunidades de desarrollo comercial, económico y social; la ausencia de inversión de la industria guatemalteca en tareas de investigación o innovación ante la

\footnotetext{
2 Además de esta instancia que recibe alrededor de 20 millones de quetzales existe otra que se encarga dentro del mismo organigrama de los Servicios Administrativos y de Seguridad de la Presidencia de la República que recibe un presupuesto anual alrededor de 150 millones de quetzales.

3 Integra a la SENACYT y a la CONCYT.
} 
inexistencia de incentivos fiscales y de otros instrumentos de política económica; así como la inversión notablemente limitada en actividades de investigación y desarrollo que representa únicamente al 0.0029\% del Producto Interno Bruno (PIB), 14 veces menos que el promedio de inversión de África Subsahariana, 25 veces menos que el promedio de América Latina y el Caribe y 85 veces que el promedio de Europa Occidental.

Si lo anterior no fuese suficiente para ilustrar el estado de la ciencia y tecnología en Guatemala, la UNESCO (2017) expone un ejemplo contundente que dimensiona el descuido nacional en la materia:

"La República de Malaui, tiene una superficie y población similar a Guatemala, pero su PIB es 10 veces más pequeño (o sea que es un país 10 veces más pobre). En un estudio GO-SPIN de Malaui, se comprobó que el país invierte al menos 3 veces el presupuesto nominal de Guatemala en I+D. También, produce 3 veces más publicaciones científicas que su par centroamericano. Cuatro décadas atrás, en la propia Guatemala, se invertía casi 8 veces más de lo que se invierte hoy en I+D como porcentaje del PIB".

Si bien en principio la reducida participación del INE y la SENACYT en la asesoría científica para la gestión de la pandemia se encuentra en las limitaciones presupuestarias e institucionales como se señaló anteriormente, más allá de dichos antecedentes, los roles que desempeñaron finalmente también encuentran explicación en la poca relevancia que tuvo la asesoría científica en su conjunto para el gobierno central, tal y como se argumenta a lo largo de este artículo.

\subsection{La reacción pronta del gobierno central}

Uno de los consensos primarios de los científicos durante el primer semestre de 2020 fue la importancia de la detección temprana y la capacidad de distribuir los contagios en el transcurso del tiempo para que los gobiernos obtuvieran resultados óptimos en la contención de la tasa de contagios y, especialmente, de la tasa de mortalidad del virus. El gobierno central liderado por Alejandro Giammattei estableció tres medidas de alerta temprana, antes e inmediatamente después de la aparición del primer caso, influido en mayor medida por la experiencia internacional que por el consejo científico interno a cargo en aquel momento de la Asociación Guatemalteca de Enfermedades Infecciosas (AGEI) y del Ministerio de Salud Pública y Asistencia Social (MSPAS).

Las medidas de prevención y reacción temprana que consistieron en el control aduanero de los pasajeros que ingresaban al Aeropuerto Internacional La Aurora, el confinamiento parcial durante dos semanas y el establecimiento del toque de queda a partir de las 4 de la tarde en un período de menor circulación de personas y capitales, pudieron contener la escalada de los casos de la primera ola y darle un respiro al sistema de salud durante 28 días. Entre el 13 de marzo y 
el 13 de abril, el encadenamiento de los contagios mantuvo un comportamiento lineal, registrándose únicamente 167 casos con una tasa de mortalidad del 4.29\% según los datos del MSPAS (Velásquez Pérez, 2020). Estas medidas fueron acertadas y los resultados satisfactorios, al menos hasta el 18 de abril con la aparición del primer caso comunitario, cuando comenzó a cambiar el ritmo de los contagios e incluso el abordaje de la enfermedad dependiendo del lugar de origen, en donde se observaron expresiones de estigmatización y discriminación amparadas en los cordones sanitarios (Prensa Comunitaria, 2020; García, 2020)

Fue la primera ola de contagios la que advirtió por las dificultades de cobertura, recursos y decisiones sobre la marcha que generó, que la experiencia internacional y las débiles capacidades profesionales de las autoridades de salud, acostumbradas a ser nombradas por pago de favores políticos y deudas electorales, no serían suficientes para enfrentar la emergencia sanitaria; conllevando al presidente a formar la Comisión Presidencial de Atención a la Emergencia Covid-19 (Coprecovid) dos meses después cuando el país atravesaba los 1,200 casos activos que se concentraban en las principales áreas urbanas ${ }^{4}$ del territorio nacional.

\section{La asesoría científica en la gestión de la pandemia}

\subsection{La situación general de los asesores científicos}

Si bien la insuficiencia y la incapacidad del Ministerio de Salud a cargo de Hugo Monroy $^{5}$, cuyas características se mencionarán más adelante, fueron las razones señaladas por los medios de comunicación y la sociedad civil para conformar la Coprecovid y dar un cambio de giro en la gestión de la pandemia, las razones oficiales para crearla según el Acuerdo Gubernativo que le dio vida fueron para "ayudar, recomendar, facilitar, asesorar y coadyuvar en las acciones, mecanismos, medidas y protocolos implementados por el Ministerio de Salud Pública, así como otras dependencias del Ejecutivo, para la prevención, contención y mitigación del Covid-19".

Cuando el doctor Edwin Asturias fue designado el 19 de mayo para dirigir la Coprecovid $^{6}$, la decisión fue percibida como un acierto, aunque demasiado tardío, y como un reconocimiento sobre la importancia de la ciencia en la gestión de la pandemia, una actitud poco usual en el entorno político nacional. Especialmente porque el Comisionado cursó sus estudios de especialización en enfermedades infecciosas en la Universidad de Johns Hopkins, una institución de excelencia académica en materia de salud y que durante la emergencia sanitaria mundial se ha

El $86 \%$ de los primeros 50 casos provenían de áreas urbanas.

Quien había sido designado al cargo en compensación de no poder alcanzar una curul legislativa tras las elecciones generales de 2019.

6 Sus funciones iniciaron hasta el 3 de junio. 
destacado por la generación de información, la proyección de cifras y la investigación de fórmulas para comprender la evolución espacial del virus.

Pero también porque un profesor de enfermedades infecciosas y de epidemiología en el Hospital de la Universidad de Colorado y miembro de la Sociedad Americana de Enfermedades Infecciosas que combinaba la perspectiva clínica y la de salud pública ${ }^{7}$ estaría a cargo de una Comisión que fue presentada como la principal consejera científica de las decisiones sanitarias que serían implementadas por el Ministerio de Salud Pública y porque la visión que defendía en los medios de comunicación y en las redes sociales hasta cuatro días antes de ser designado era que el gobierno debía de "dar el ejemplo convocando a sus mejores científicos, economistas, estrategas para poder tener un plan que todos los ciudadanos, hasta los que no saben leer, comprendan y se sientan responsables de cómo ayudar a contener la ola que se viene" (Ortiz, 2020).

Esa dimensión multidisciplinaria de la asesoría científica en la gestión de la pandemia no sucedió. Los criterios técnicos y científicos fueron relegados en la toma y la implementación de decisiones políticas y de política pública; además, el campo de acción de instituciones como el Instituto Nacional de Estadística y el Sistema Nacional de Ciencia Tecnología dentro de la articulación interinstitucional para la asesoría científica fue considerablemente reducido, sobre todo, en comparación a sus competencias nacionales y a las funciones que desempeñaron estas instituciones en otros países de la región. El rol de la SENACYT se limitó a la realización de un reto de innovación y a la discusión de posibles líneas de investigación para atender la emergencia sanitaria. Únicamente prosperó la primera, pero sus resultados fueron cuestionados por la carencia de argumentación científica en los proyectos de investigación que se seleccionaron. El concurso Reto de Innovación Abierta COVID-19 realizado entre el 20 de marzo y el 6 de abril tenía como objetivo reunir propuestas innovadoras para atender algunas problemáticas originadas de la pandemia, de las cuales se seleccionarían los mejores y desde el gobierno se les gestionaría recursos para ponerlos en práctica.

De los 234 proyectos presentados, la SENACYT seleccionó 7, y fue el proyecto ganador el que provocó las críticas más relevantes. Si bien los criterios de evaluación contemplaban que debían ser técnicamente viables, que contaran con grados de avances para poderlos implementar a corto plazo, que tuvieran impacto inmediato y que no fueran financieramente prohibitivos; la química bióloga Paula Castellanos, con amplia experiencia y trayectoria nacional e internacional en inmunohematología y bancos de sangre, planteó en un documento con el apoyo del Grupo Cooperativo Iberoamericano de Medicina Transfusional una serie de argumentos técnicos

Como asegurara Lucrecia Hernández Mack, exministra de salud, experta en salud pública y diputada al Congreso de la República (2020-2024), en un diálogo sostenido con Edwin Asturias el 2 de mayo sobre el comportamiento del covid-19 en Guatemala. 
y científicos en rechazo al proyecto TAMI Transfusión Autóloga para pacientes con COVID-19 en el que Castellanos (2020) concluye que:

"Está muy lejos de cumplir con los mínimos criterios metodológicos, científicos y éticos aceptables para alcanzar un beneficio terapéutico, y lejos de ello puede arriesgar en gran medida la vida de los pacientes infectados por la pandemia del COVID-19" (p.1) dado que es completamente anti-científico sostener que después de 72 horas que el paciente quede inmunizado podrá donar sangre y salir de la cuarentena, ya que como lleva un toxoide, el virus dejará de ser inefectivo y al mismo tiempo tendrá la capacidad de inmunizar a las personas a su alrededor, demostrando que "el citado profesional no tiene ningún conocimiento en inmunología, virología y la medicina transfusional que está proponiendo" (Castellanos, 2020:8)

Chang (2020), por su lado, tras la publicación de una entrevista del medio Plaza Pública a la directora de la SENACYT señaló el incumplimiento de los criterios de evaluación que a su juicio desnudan las deficiencias de la institución y a su vez sirven de referencia para comprender el papel tan reducido que la Secretaría ejerció durante la gestión de la emergencia. La primera es la opacidad en la elección del jurado calificador prescindiendo de las comisiones del SINCYT y de sus contactos profesionales; la segunda es la confusión respecto a las razones bajo las cuales se califica un proyecto dado que cuando se le preguntó por las falencias científicas y los errores en el uso de términos académicos sostuvo que su aceptación o rechazo fue una cuestión de opinión y que respetaba la libre emisión del pensamiento, eludiendo por completo que en realidad debía ser una cuestión de cumplimiento de requisitos objetivos.

Por último, Chang (2020) señaló la incoherencia en el procedimiento de selección, ya que cuando se le preguntó respecto a si valía la pena esperar un proyecto que está confundiendo términos básicos de ciencia y plantea la extracción de sangre a un paciente justo cuando está débil, la directora de la SENACYT respondió que se debía esperar a que terminara la revisión de pares para concluir si el proyecto contaba con base científica o no. Lo cual implica que reconoció que el proyecto se eligió sin un análisis de viabilidad previo. Contrario a lo que sucedió en Panamá, por ejemplo, donde un equipo de investigación multidisciplinario proveniente de instituciones públicas, privadas y del tercer sector realizaron un estudio aprobado por el Comité Nacional de Bioética de la Investigación y apoyado por su SENACYT en el que evaluaron las conductas de salud y alimentación durante el confinamiento de 1,561 participantes.

En cuanto al INE, mientras otros institutos de estadística se han dedicado a la recopilación de información estadística relacionada a la situación económica, social y demográfica durante la emergencia sanitaria, el INE únicamente llevó a cabo un análisis entre el 28 de septiembre y el 2 de octubre sobre el uso correcto de mascarillas en el marco de un estudio de mercados y negocios en el que estableció 
que el $35.5 \%$ y el $28.6 \%$ de personas de la región del nor-occidente y la región central respectivamente no utilizan correctamente la mascarilla. Los datos fueron presentados en redes sociales por el Ministerio de Economía el 5 de octubre y cuatro días después por el Ministerio de Salud Pública en una conferencia de prensa en donde la ministra mencionó que se estaban realizando acercamientos con las municipalidades para diseñar las estrategias de corrección sobre su uso. Sin embargo, a la fecha no habían explicado en qué consistieron y de qué manera utilizaron la información para diseñarlas o llevarlas a cabo.

Hasta el propio Edwin Asturias y la Coprecovid sucumbieron ante las actitudes autoritarias del presidente y sus compromisos adquiridos durante la campaña electoral. La oposición parlamentaria y las iniciativas ciudadanas como Laboratorio de Datos GT (Labdatosgt) identificaron inconsistencias en los argumentos con los que justificaban el diseño y la implementación de las medidas de mitigación. Los cuales respondían más a valoraciones de orden político que a criterios técnicos y científicos, a pesar de que el Comisionado sostenía en las citaciones y en las reuniones que se guiaba por las publicaciones científicas que iban surgiendo en distintas universidades.

La explicación de la contradicción señalada con anterioridad se encuentra en el modo en el que el presidente Giammattei ha ejercido sus funciones ejecutivas, caracterizadas por gobernar bajo estados de excepción o de sitio con el acuerdo y el consejo exclusivamente de Centro de Gobierno, una institución que dirigió su persona de mayor confianza y que en la práctica usurpó las funciones de la Vicepresidencia de la República hasta diciembre de 2020, así como en las declaraciones off the record del personal de la Comisión, quienes señalaron que la toma de decisiones habían sido bipolares debido a que Asturias tenía una actitud demasiado complaciente con las peticiones del presidente.

Como se observará en el análisis del contenido de la política sanitaria y de la política laboral que se abordan a continuación, las decisiones de política pública estaban ancladas en realidad a los intereses económicos de las gremiales y a la intuición personal del presidente, provocando que la asesoría científica no fuese vinculante cuando era contundente, y quedara relegada frente a la relación entre el gobierno y la élite empresarial.

\subsection{La política sanitaria: confinamiento y reapertura}

La política sanitaria en materia de confinamiento y reapertura dentro del período analizado se dividió en cuatro momentos. El primero corresponde al período del 13 marzo al 19 de abril, el segundo del 20 de abril al 2 de junio, el tercero del 3 de junio al 11 de julio y el cuarto del 12 de julio con la presentación del Semáforo Epidemiológico a la fecha. El primer momento fue descrito a grandes rasgos en el apartado de la reacción pronta del gobierno, no obstante, cabe resaltar que este período también estuvo caracterizado por el negacionismo del presidente respecto a 
la importancia de la masificación de las pruebas asegurando que era inconveniente ${ }^{8}$; así como por la poca información que aportaban los datos públicos generados por el Ministerio de Salud Pública debido a que no se encontraban clasificados según el lugar de origen del contagio, el circuito de movilidad del contagiado, la ubicación geográfica y territorial ni por el grupo etario al que pertenecía, provocando una sensación de desconfianza y una narrativa social de la posibilidad de subregistro que impactaría en el conteo real de los casos.

Tras las dos semanas de confinamiento parcial las medidas se fueron flexibilizando, especialmente, a favor de algunos sectores económicos. Esta desigualdad en la aplicación de las medidas tenía su razón de ser en la distancia que el presidente había tomado de la AGEI y de otros expertos reconocidos en la materia. Para el 10 de abril, prácticamente a un mes del primer caso, únicamente se había reunido una vez con ellos y tomaba decisiones contrarias a las recomendaciones que estos actores realizaban públicamente. Por ejemplo, la decisión de no masificar las pruebas y centralizarlas en el Laboratorio Nacional contrastaba con la recomendación de Eduardo Arathoon, uno de los infectólogos con los que el presidente se reunió el 14 de marzo, quien sostenía en una entrevista realizada por Gutiérrez Valdizán (2020) de Agencia Ocote que debían aumentarse y descentralizarse las pruebas en virtud de que el 20\% de las personas eran asintomáticas, por lo cual seguir esta recomendación permitiría el control epidemiológico y la respuesta clínica a los contagiados. Incluso en la misma nota periodística cuando le preguntaron si el presidente tenía asesores respondió que sí, que no eran adecuados y que debía asesorarse de gente científica que sabía lo que estaba haciendo, pero que no estaban siendo convocados porque se estaban anteponiendo intereses económicos mezquinos a la salud de las personas.

Como se observaría en el segundo momento que iniciaría tras la reducción del tiempo del toque de queda de las 4 a las 6 de la tarde, una acción calificada como poco asesorada y que el presidente justificó asegurando que la había consensuado con la AGEI, más que un subregistro lo que existía era desorganización en la forma en la que registraban los casos, lo cual impedía determinar con mayor certeza y confiabilidad la rapidez del contagio, las procedencias de los contagiados, así como las cantidades reales de los contagios, las recuperaciones y los fallecidos; y, por tanto, de las proyecciones y de los estudios que se pudieran realizar a partir de dicha información.

Este fue el momento que presionó al presidente a crear una Comisión y acudir a un científico con vasta experiencia en la materia. No solo por la profundización de la desconfianza hacia los datos básicos que reportaba el MSPAS y la comprobada incapacidad de su ministro Hugo Monroy, quien dejó sin cobertura del sistema de salud a todas las patologías que no fuesen el virus, sin abastecimiento de insumos

Debido a que hoy le podían hacer las pruebas y dar negativo, pero mañana salir infectado si no se cuidaba. 
para la atención de la emergencia y sin amplia información estadística sobre los casos registrados; sino también por la falta de una asesoría científica oficialmente integrada, que fuese considerada y realizada de manera rutinaria y sistemática.

La disonancia entre la asesoría científica proveniente de la AGEI y el presidente se pudo observar, por ejemplo, en las declaraciones de Nancy Sandoval Paiz, la presidenta de la Asociación ${ }^{9}$, quien aseguró tras la justificación de Giammattei en cadena nacional, que se habían reunido únicamente tres veces ${ }^{10}$ para darles su opinión y que su recomendación en la última había sido mantener la cuarentena, el toque de queda original y el cierre de centros comerciales, pero que era el gobierno el que tomaba la decisión (Mazariegos Rivas, 2020). Esa actitud de invitar a expertos y no escucharlos se repetiría durante toda la gestión de la pandemia.

El extremo de la falta de asesoría técnica y científica o de no escucharla se reflejaba en la presentación de los datos hasta finales de junio en medio del tercer momento, en donde en ningún instante figuró ni el INE ni la SENACYT, los cuales pudieron haber contribuido tanto en el análisis de datos como en las recomendaciones de política pública. Durante la confirmación de los primeros casos entregaron información sensible como los nombres de los pacientes. Lo cual provocó una serie de críticas dada la estigmatización y la vulnerabilidad a la que habían expuesto a las personas, ya que incluso provocó conflictos sociales en las comunidades a las que pertenecían aquellos, amenazas e intentos de sacar a sus familias de sus hogares. Tras la polémica suscitada no entregaban ningún tipo de dato más que la cantidad de contagiados, fallecidos y recuperados, argumentando que era información sensible aun cuando los periodistas, los tanques de pensamiento, los profesionales autónomos y la ciudadanía en general no estaban solicitando nombres ni direcciones de residencia, pero sí, por ejemplo, datos abiertos que permitieran rastrear el encadenamiento de los contagios.

Óscar Chávez, coordinador de Labdatosgt, señaló en una entrevista a Prensa Libre que la plataforma nació precisamente al advertir que la información era insuficiente y poco útil para dimensionar la situación real de la epidemia, pero también porque era opaca e inconsistente, especialmente, lo relacionado a la cantidad de pruebas que el gobierno realizaba, ya que aseguraba que obtenían los datos de varias fuentes incluso oficiales y generalmente no cuadraban. Lo cual demostraba que la sensación de desconfianza además de legítima, también era apegada a la realidad. Sin calidad y sin certeza, la información con que contaba el gobierno para tomar decisiones sanitarias era deficiente, desactualizada e inexacta.

Los efectos negativos que produjo la reducción del toque de queda y la flexibilización a favor de los sectores económicos, al punto de registrarse 176 casos en un solo día

\footnotetext{
9 Hasta la llegada de la Coprecovid fungieron de manera informal la asesoría "externa”, mientras que la "interna” estaba a cargo del ministro del MSPAS.

10 Entre el 13 de marzo y el 18 de abril de 2020.
} 
y un crecimiento del 194\% en tan solo una semana, forzó al presidente a decretar el 14 de mayo un nuevo confinamiento total de dos fines de semana consecutivos sin posibilidad de que las personas se pudieran movilizar ${ }^{11}$, restringió la movilidad interdepartamental con excepción de los servicios vitales y por razones laborales, y aumentó el toque de queda a partir de las 5 de la tarde. Estas medidas fueron bien valoradas por la comunidad de infectólogos, aunque nuevamente hicieron notar la tardanza, en virtud de que fueron tomadas tras la explosión de los casos comunitarios y de la expansión del encadenamiento de los contagios inter e intradepartamentales.

Además, las medidas duraron únicamente dos semanas y aunque algunas se mantuvieron como la restricción de la movilidad departamental, se distorsionó el espíritu de distanciamiento social tanto en el contenido como en la práctica. El 31 de mayo volvió a reducir el toque de queda a partir de las 6 de la tarde aduciendo el congestionamiento por lluvias, levantó el confinamiento durante los fines de semana, anunció el inicio de operaciones de la Coprecovid y en medio de la fase de mitigación aseguró que durante esa semana se comenzaría a preparar el regreso a la nueva normalidad. En realidad, a excepción de las universidades, los grandes centros comerciales, el aeropuerto y los centros de trabajo que trasladaron sus operaciones a distancia, las actividades públicas y privadas con aforos reducidos o controlados se mantuvieron abiertas prácticamente durante toda la gestión de la pandemia de 2020, aunque afectando claramente al sector de la economía informal anclada al espacio público cuya reactivación se fue dando de una manera lenta en comparación a otras actividades económicas.

El tercer momento comenzó con el inicio de operaciones de la Coprecovid. Más allá de las razones oficiales y mediáticas mencionadas en la situación general de los actores de asesoría científica, cuando se analiza en retrospectiva, la razón política para conformarla fue con el objetivo de justificar y blanquear el regreso a la nueva normalidad, que permitiera en palabras del presidente "la desescalada del confinamiento y reapertura gradual de la industria, el comercio y el resto de actividades sociales". La decisión de política pública, como se observará en el apartado de la política laboral, estuvo mayoritariamente anclada a los intereses económicos de los grandes capitales. En el contexto de esa intencionalidad, la asesoría científica podía asegurar que en el corto plazo $^{12}$ se pudieran elaborar los protocolos que deseaba el presidente para que las actividades se terminaran de liberalizar por medio de consejos de seguridad ocupacional para el Ministerio de Salud Pública y el Ministerio de Trabajo y Previsión Social (Mintrab).

11 El fin de semana del 15 al 18 de mayo se permitió asistir a pie a las tiendas de barrio y abarroterías de 8 a 11 de la mañana.

12 Contrario a lo que mencionó el presidente en la cadena nacional del 31 de mayo. 
Durante este período se observó el pico más alto de contagios. El 19 de junio había sido destituido el ministro Monroy ${ }^{13}$, además de las críticas que fueron señaladas anteriormente, por haber ocultado el fallecimiento de 38 personas. Para el 30 de junio en un país de 17 millones de personas se estaban alcanzando los 20,700 casos, 13 veces más de los que se habían registrado un mes y medio antes. Dos días después se registraron alrededor de 1,300 casos, la cantidad de contagiados más alta en un mismo día dentro de la evolución y el comportamiento del encadenamiento en 8 meses. Si la fase de mitigación quedó entredicha debido a que Guatemala fue el primer país de Centroamérica con 1,000 muertes por el virus, el plan de reapertura presentado por Edwin Asturias el día que tomó posesión quedó reducido a una ruta de formulación de protocolos de seguridad ocupacional que ni siquiera respetó los 14 días de descensos consecutivos que serviría como condición sine qua non para entrar a la Fase Intermedia, previa a la Fase de Apertura a la Nueva Normalidad.

Si bien el Comisionado de la Coprecovid reconocía y aconsejaba públicamente la necesidad de aumentar el número de pruebas, el gobierno central no pudo por incapacidad o negligencia hacer cambios notables en la materia. Durante el pico más alto, entre finales de junio e inicios de julio, alcanzó una presa de 30 mil pruebas pendientes según la estimación de Labdatosgt que fue calculada de la relación de la fecha de toma de muestra y la fecha de toma de resultados (Chávez, 2020). Lo cual implicaba el retraso hasta de dos semanas del conocimiento del resultado, sin que las personas testeadas estuvieran cumpliendo medidas de confinamiento o distanciamiento social. Pero, además, según el coordinador de Labdatosgt, la asesoría científica de la Comisión falló porque hasta noviembre no había logrado realizar un análisis del cuello de botella y del proceso de la cadena de las pruebas que les permita advertir lo que podría ocurrir en una segunda ola.

El cuarto momento se inicia el 12 de julio con la presentación del Semáforo Epidemiológico. Si bien tras las contradicciones en torno a las medidas tomadas e implementadas se había creado un clima de críticas y distanciamientos entre los distintos actores sociales, políticos y científicos, la puesta en marcha del Semáforo terminó constituyéndose en el punto de quiebre definitivo respecto a la confianza que la oposición política, la ciudadanía y la comunidad científica había depositado en Edwin Asturias y en la Coprecovid, quienes también absorbieron en buena medida la pérdida de legitimidad del gobierno central ${ }^{14}$, especialmente, del presidente y de su capacidad dirigente. No solo por las medidas sanitarias contradictorias sino también por la incapacidad de los Ministerios para garantizar la cobertura y la eficacia en

13 Fue reemplazado por Amelia Flores, maestra en Epidemiología y Salud Pública y con una trayectoria de más de 30 años en Salud Pública como jefa del Laboratorio Nacional de Microbiología, directora general de Servicios de Salud y viceministra técnica del MSPAS.

14 Al punto de que la población y analistas pusieron en duda si realmente el contagio del presidente fue verídico como se reportó el 19 de septiembre o fue una estrategia para recuperar confianza desde la empatía. 
la implementación de los programas sociales que tenían como objetivo mitigar las consecuencias sociales y económicas de la pandemia.

Las falencias en la entrega, visualización y generación de información útil permanecieron hasta finales de julio cuando el pico más alto de contagios ya había pasado y la Coprecovid decidió crear un Tablero sobre la Situación del Covid-19 en el país (Ministerio de Salud Pública y Asistencia Social, 2020). Si bien Chávez (2020) consideró que es el mejor tablero de Centroamérica compartiendo podio con Costa Rica, sostuvo que los datos disponibles no se utilizan para identificar a las poblaciones más vulnerables ni para utilizarlos en la toma de decisiones. Incluso ironiza con que solo son utilizados por la Comisión para elaborar sus presentaciones y por los tanques de pensamiento para realizar sus análisis. Pero además también señaló que el reporte de los casos tiene un problema similar al descrito en el déficit de la entrega de los resultados debido a que la Coprecovid y el Ministerio de Salud Pública han sido incapaces de ampliar la cantidad de digitadores para realizar una auditoría, provocando que cada día se estén alterando los datos de los días anteriores a la última fecha oficial reportada, alcanzando un retraso hasta de 10 días. Cuya cantidad asegura Chávez (2020) "no es la mejor ni la peor, pero sí demuestra que existe un proceso ineficiente en el reporte de los casos".

El Semáforo fue presentado quince días antes que entrara en vigencia, junto con la reducción del toque de queda a partir de las 9 de la noche, como un sistema de alertas sanitarias que definirían la escalada o desescalada de las restricciones nacionales, regionales, departamentales y municipales determinadas por el MSPAS a partir de la cantidad de casos por cada 100 mil habitantes o del porcentaje de pruebas positivas. Las categorías creadas bajo la asesoría de Coprecovid que regirían en cada territorio dependiendo del comportamiento de los contagios fueron máxima, alta, moderada y nueva normalidad.

Tabla 1

Sistema de alertas sanitarias

\begin{tabular}{|l|l|}
\hline Categoría & \multicolumn{1}{c|}{ Criterios } \\
\hline Rojo: Máxima & $\begin{array}{l}\text { 25 casos por cada 100 mil habitantes o que el 20\% de las } \\
\text { pruebas sean positivas. Restricción total del transporte } \\
\text { público, circulación de vehículos por número de placa, } \\
\text { cierre de centros comerciales y prohibición de todas las } \\
\text { actividades sociales. }\end{array}$ \\
\hline Naranja: Alta & $\begin{array}{l}\text { Entre 15 y 24 casos por cada 100 mil habitantes, o entre } \\
15 \text { y 20\% de pruebas positivas. Se comenzará el trans- } \\
\text { porte público parcial y habrá apertura limitada de secto- } \\
\text { res económicos como centros comerciales, pero siempre } \\
\text { con las medidas de prevención. }\end{array}$ \\
\hline
\end{tabular}




\begin{tabular}{|l|l|}
\hline Categoría & \multicolumn{1}{c|}{ Criterios } \\
\hline Amarillo: Moderada & $\begin{array}{l}\text { Entre 5 y 14 casos por 100 mil habitantes, o entre 5 y } \\
14 \% \text { de pruebas positivas. Flexibilidad de la mayoría de } \\
\text { las actividades económicas para evitar regresar a las alertas } \\
\text { naranja y roja. }\end{array}$ \\
\hline Verde: Nueva normalidad & $\begin{array}{l}\text { Menos de 5 casos por cada 100 mil habitantes, o 5\% de } \\
\text { pruebas positivas. Operación bajo las normas de la nueva } \\
\text { normalidad de todos los sectores. }\end{array}$ \\
\hline
\end{tabular}

Fuente: elaboración propia sobre la base de la información obtenida en Marroquin (2020)

Irónicamente fue precisamente el Semáforo el mejor ejemplo de que la evidencia estaba siendo descartada en la priorización de recursos y en la definición e implementación de la política sanitaria por territorio y en su conjunto. En primer lugar, por el incumplimiento de la meta de 5,000 pruebas diarias y la falta de desagregación municipal de las pruebas realizadas, lo cual constituye un vacío en la vigilancia epistemológica que ha impedido afirmar con certeza el nivel de contagios y el comportamiento de la pandemia por cada 100 mil habitantes, criterios fundamentales para establecer las restricciones pertinentes.

En segundo lugar, porque como se señaló anteriormente, la generación de estadísticas del manejo epidemiológico había sido deficiente y ponía en duda las categorizaciones creadas para definir las restricciones o las liberalizaciones. En tercer lugar, porque en la práctica se habían liberalizado todas las actividades independientemente del color del territorio, abriendo paso a la realización de eventos súper contagiadores sociales, religiosos y culturales. Especialmente a partir del levantamiento del toque de queda y del Estado de Calamidad Pública el 5 de octubre, dejando al Semáforo sin efectos prácticos dado que se había terminado la excepcionalidad legal para establecer ciertas restricciones, especialmente, relacionadas a la movilidad y la autorización de actividades públicas y privadas.

Dos expresiones más de las falencias de la asesoría científica desde Coprecovid se pueden observar en el diseño institucional y la articulación interinstitucional. La primera porque como se mencionó anteriormente en retrospectiva, no se creó con la visión de que fuera una entidad técnica de asesoría vinculante, sino que fue una decisión política para cubrir el hecho de que se le estaba exigiendo al gobierno respuestas técnicas y científicas, así como para blanquear el favorecimiento de las políticas hacia los sectores económicos hegemónicos. Pero también porque en cierta forma duplicaba funciones con el Centro Nacional de Epidemiología del Ministerio de Salud Pública en cuya responsabilidad recae el diseño y la implementación de la política sanitaria, especialmente, la prevención y la regulación de espacios públicos, privados y centros de trabajo a través de su sistema de alertas y su vigilancia epidemiológica. 
En la segunda porque se implementó una política sanitaria totalizadora desde el gobierno central que redujo el margen de maniobra de las municipalidades, cuyo conocimiento e información instantánea de sus territorios es mayor; pero además evidenció la falta de trabajo en conjunto al punto de que las municipalidades y los centros de operación de emergencia no han utilizado los datos del MSPAS ${ }^{15}$, así como las dificultades económicas e institucionales para sostener las decisiones locales cuando existieron y cuando en ocasiones sí existieron fueron incluso con mayor respaldo científico de asociaciones civiles y tanques de pensamiento.

Tabla 2

Comparación de la gestión de la pandemia en Centroamérica

\begin{tabular}{|l|c|c|c|c|c|}
\hline País & $\begin{array}{c}\text { Contagiados } \\
\text { fallecidos }\end{array}$ & $\begin{array}{c}\text { Total de } \\
\text { contagiados }\end{array}$ & $\begin{array}{c}\text { Tasa de } \\
\text { mortalidad } \\
\text { sobre el } \\
\text { total de } \\
\text { contagiados } \\
\mathbf{( \% )}\end{array}$ & $\begin{array}{c}\text { Tasa de } \\
\text { mortalidad } \\
\text { por cada } \\
\mathbf{1 , 0 0 0} \\
\text { habitantes } \\
\text { contagiados }\end{array}$ & $\begin{array}{c}\text { Tasa de } \\
\text { mortalidad } \\
\text { por cada } \\
\mathbf{1 0 0 , 0 0 0} \\
\text { habitantes }\end{array}$ \\
\hline Panamá & 3,039 & 163,453 & 1.86 & 18.59 & 72.76 \\
\hline $\begin{array}{l}\text { Costa } \\
\text { Rica }\end{array}$ & 1,690 & 137,093 & 1.23 & 12.33 & 33.81 \\
\hline Nicaragua & 160 & 5,784 & 2.77 & 27.66 & 2.47 \\
\hline Honduras & 2,905 & 107,513 & 2.70 & 27.02 & 30.30 \\
\hline $\begin{array}{l}\text { El } \\
\text { Salvador }\end{array}$ & 1,111 & 38,405 & 2.89 & 28.93 & 17.30 \\
\hline Guatemala & 4,161 & 121,798 & 3.42 & 34.16 & 24.44 \\
\hline
\end{tabular}

Fuente: elaboración propia con base en la información de fallecidos y contagiados obtenida en Johns Hopkins University (2020).

Como se puede observar, Guatemala hasta noviembre tenía los peores datos de la región ${ }^{16}$, especialmente los relacionados directamente al tratamiento de los contagiados, lo cual revela deficiencias en el sistema de salud pública. Si bien en lo referente a la mitigación, es el tercer país con mayor tasa de contagios detrás de Costa Rica y Panamá, el país puntea en la cantidad de contagiados fallecidos, en la tasa de mortalidad por cada 1,000 habitantes contagiados y en la tasa de mortalidad

15 Evidenciando de esa manera, como aseguró el coordinador de Labdatos, que, aunque se respetaran los procesos de la cadena de las pruebas, el reporte de los contagios y la asesoría científica desde Coprecovid no serviría de nada porque no existen articulaciones interinstitucionales compactas y alineadas.

16 Los datos de Nicaragua deben valorarse con reservas en virtud del régimen autoritario competitivo que gobierna el país, que se ha caracterizado por la opacidad en la presentación de la información y criticado por el posible ocultamiento de las cifras. 
sobre el total de contagiados que incluso se encuentra por encima de la tasa de mortalidad promedio mundial que rondaba alrededor del $2.33 \%$.

\subsection{La política laboral: liberalización y hacinamiento}

Es en la política laboral en donde se evidencia que la política sanitaria obedeció más a los intereses corporativos que a los criterios técnicos y científicos de orden epidemiológico. La autorización de las empresas, por ejemplo, fue una competencia absoluta del Ministerio de Economía (Mineco) que solo mantuvo durante dos semanas y aplicó para actividades de maquila, manufactura, no agropecuarias, comercio y desarrollo comercial e industrial. En esta competencia se hallaban al menos tres debilidades estratégicas.

La primera es que las autorizaciones fueron automáticas con verificaciones a posteriori que carecerían de un plan de muestreo que permitiera representar una parte significativa del universo de empresas autorizadas para establecer los porcentajes de incumplimiento de las medidas sanitarias y de seguridad ocupacional. De las 8,956 empresas autorizadas para operar hasta el mes de abril en donde las 10 empresas más grandes ${ }^{17}$ reportaron entre 5,300 y 7,500 empleados ${ }^{18}$ ( $9 \%$ del total), únicamente se habían realizado 74 visitas para verificar el cumplimiento de normas y regulaciones para la prevención del Covid-19. De las cuales solo tres empresas habían sido sancionadas y sin indicar cuáles habían sido esas 74 visitas para poder contrastar las características de esas empresas con los criterios para considerarla "de mayor prioridad" según lo estipulado por el Mineco y que debía haber estado en consonancia con los consejos del MSPAS y la Coprecovid ${ }^{19}$. Lo cual impedía que se corroborara si habían sido verificadas las actividades económicas más denunciadas o con mayor posibilidad de desencadenar contagios masivos.

17 La actividad reportada más grande fue la agroindustria.

18 A excepción del Ingenio Magdalena.

19 Si el INE hubiese realizado mediciones del impacto del Covid-19 habría podido aportar insumos para la toma de estas decisiones, aunque valorando la situación en retrospectiva, seguramente habrían sido ignorados. 


\section{Gráfico 1}

Las 10 empresas autorizadas más grandes

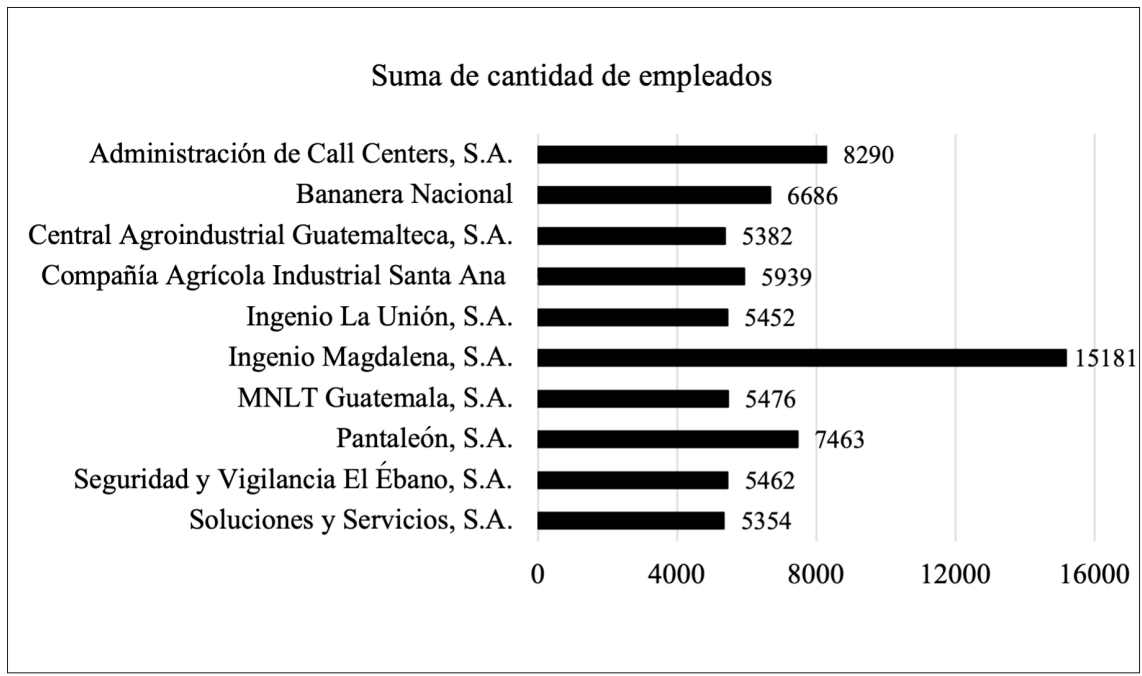

Fuente: elaboración propia sobre la base de la información obtenida de Ministerio de Economía (2020).

La segunda debilidad es que cuando el presidente le retiró la competencia al Mineco no le delegó a ningún otro ministerio o institución pública la responsabilidad de autorizar empresas y verificar el grado de cumplimiento de las medidas, por lo cual prácticamente a partir de la segunda semana de iniciadas las medidas de confinamiento parcial, todas las empresas podían operar ${ }^{20}$ y no estaban sujetas a ningún tipo de control epidemiológico o sanitario, recayendo la responsabilidad improvisada en la Inspección General de Trabajo del Mintrab dado que sus funciones constitucionales le delegan la verificación del cumplimiento de los derechos laborales. De nuevo sin ningún tipo de orientación de las instituciones encargadas de la asesoría científica.

Por ese motivo la Inspección asumió una tarea para la cual no estaba preparada, ya que contaba únicamente con 215 inspectores para cubrir el territorio nacional, no contaban con el expertiz necesario en materia de vigilancia epidemiológica para advertir más allá de lo obvio el incumplimiento de las medidas sanitarias y de seguridad ocupacional, y tampoco tenían un plan de muestreo o una meta estimada de empresas que debían ser verificadas sobre el total existente. Lo cual impedía que se pudiera establecer si la cantidad de inspectores era suficiente para cubrir la verificación del cumplimiento de la política sanitaria y la legislación laboral, así como la medición de porcentajes de incumplimiento que pudieron haber sido utilizados para corregir lo que no estuviese funcionando.

20 A excepción de las que se encontraban en centros comerciales. 
La tercera debilidad fue autorizar actividades económicas cuyos modelos de negocio tienden al hacinamiento y a la concentración de los trabajadores como las empresas textileras, de seguridad privada y los call centers debido a que aumentaban el riesgo de contagio y comprometía la vida de los grupos familiares y barriales, especialmente, la de aquellos trabajadores cuyos circuitos de movilidad continúan anclados a la relación entre el barrio y la zona industrial; y que además también forman parte de los grupos sociales de mayor vulnerabilidad dado que se desarrollan en condiciones urbanas de precariedad económica y laboral.

El mejor ejemplo de que la liberalización de actividades de este tipo eran super contagiosas y no fueran autorizadas bajo asesoría ni evidencia científica, sino por los compromisos y la presión de las cámaras empresariales fue la autorización para el funcionamiento de las empresas de textiles conocidas como maquilas. De hecho, una pregunta recurrente desde la sociedad civil, la oposición política y la comunidad científica era porqué se habían autorizado dentro de las medidas iniciales de confinamiento a una actividad que se caracterizaba por tener muchos empleados en espacios muy reducidos, que estaban reportando contagios masivos y que incluso estaban incumpliendo con la política sanitaria.

Gráfico 2

Empresas textiles autorizadas

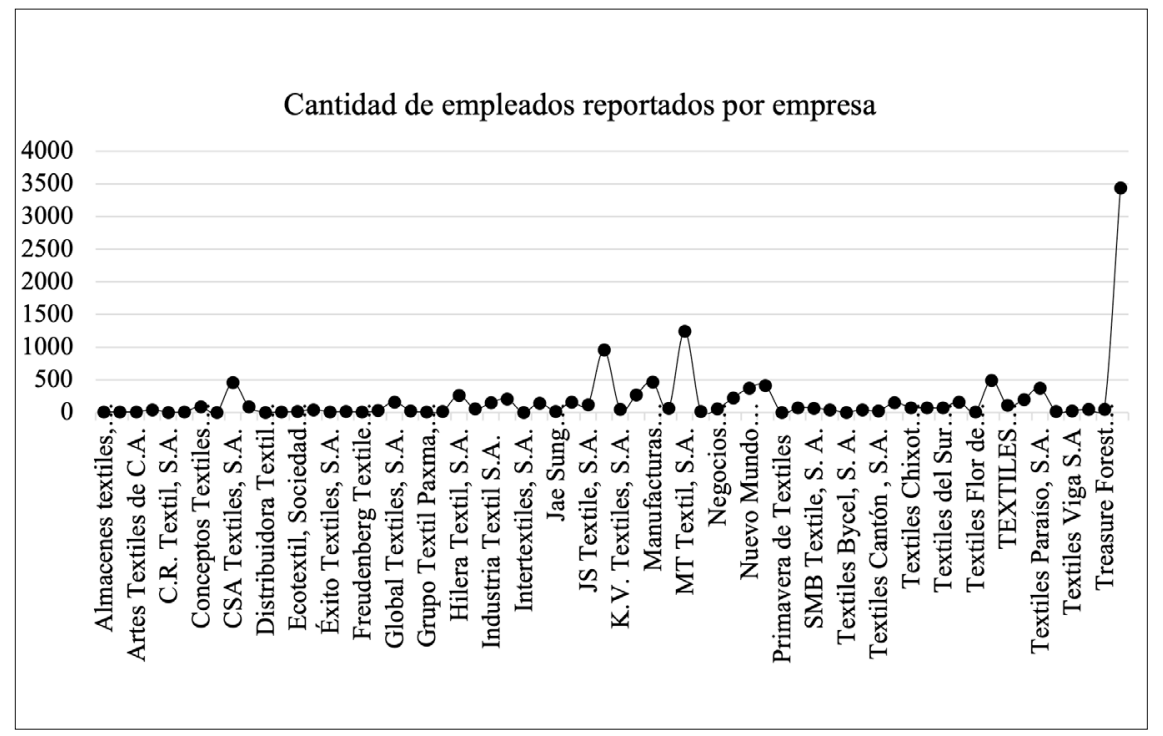

Fuente: elaboración propia sobre la base de la información obtenida de Ministerio de Economía (2020).

Tres casos que ilustran lo anterior se pueden observar en JS International, en K.P. Textil Guatemala S.A. y en Villa Nueva. En JS International tras una verificación de la Inspección General de Trabajo y la Procuraduría de los Derechos Humanos se 
hallaron violaciones a las medidas de higiene y seguridad ocupacional, y ni siquiera aparecían en la base de datos de empresas autorizadas por el Mineco. K.P Textil, la tercera empresa que más empleados había reportado ( $8 \%$ del total), anunció una cadena de contagios masivos durante la última semana de mayo. Mientras, que en Villa Nueva hasta el 1 de junio su municipalidad reportaba 257 casos y el 53\% provenía de una sola maquila.

Gráfico 3

Radiografia de las denuncias de desprotección laboral

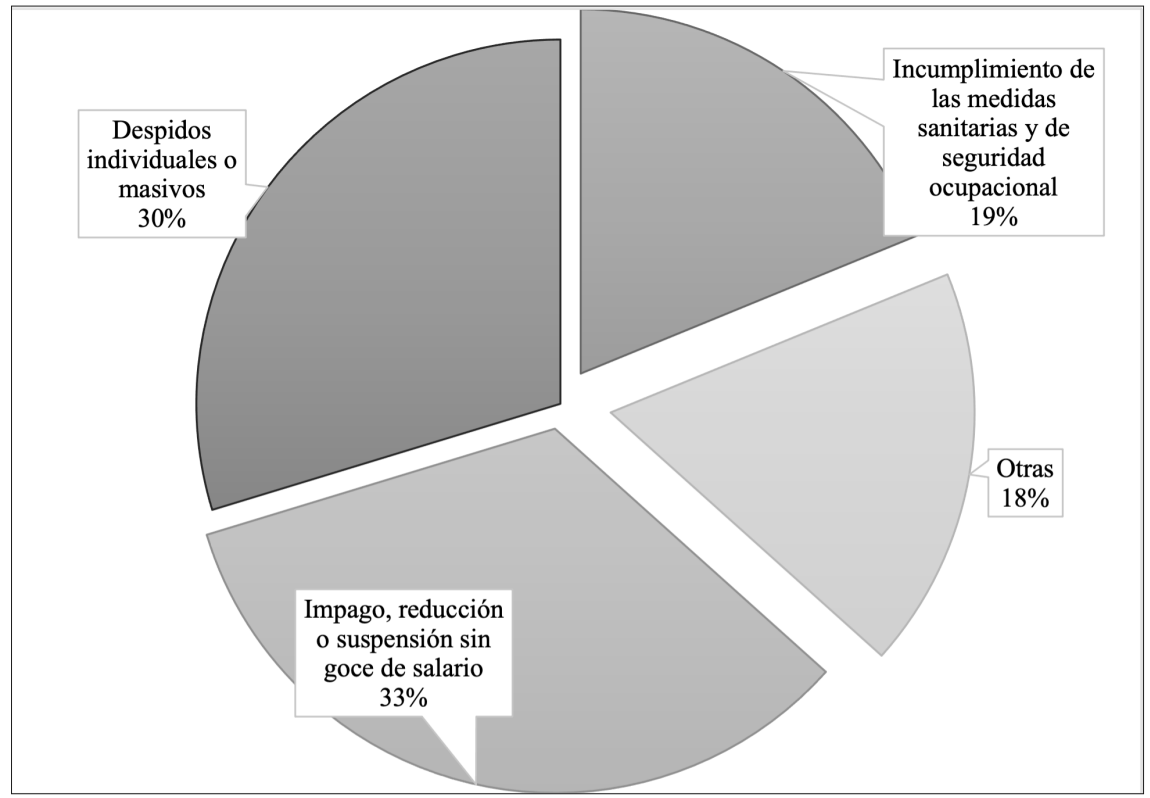

Fuente: elaboración propia sobre la base de la información de Inspección General de Trabajo (2020).

La respuesta a una decisión de política pública que fue cuestionada por la ciudadanía y la comunidad científica por sus inconsistencias en el modelo de funcionamiento se puede encontrar en el historial laboral del ministro de economía Antonio Malouf, quien había sido presidente del Comité Coordinador de Asociaciones Agrícolas, Comerciales, Industriales y Financieras (CACIF) ${ }^{21}$, de la Asociación Guatemalteca de Exportadores (Agexport), de la Comisión de Vestuario y Textiles (Vestex) y de una textilera con operaciones en Villa Nueva. Este historial que revela conflictos de interés es relevante en virtud de que el Banco Interamericano de Desarrollo concluyó en el informe "La política de las políticas públicas" (Stein, et al., 2006)

21 Una investigación de Gustavo Herrarte publicada en Plaza Pública reveló que el CACIF es más influyente que los partidos políticos en el Congreso. 
sobre el grado de influencia del empresariado en el país "el sector empresarial influye en la formulación de políticas en toda América Latina, pero en ningún lugar tanto como en Guatemala" (Stein, et al., 2006: 104).

Es evidente, entonces, de que la emergencia sanitaria cuya gestión debía estar bajo la rectoría del Ministerio de Salud Pública y la asesoría científica de la Coprecovid estuvo realmente bajo la supremacía del Ministerio de Economía, cuyas autoridades se apoyaron en la cúpula empresarial para tomar las decisiones de política pública. Al extremo de que los trabajadores de la Coprecovid aseguraban que la política sanitaria se redactaba en las oficinas del CACIF y a ellos únicamente les competía "maquillarla" para darle un supuesto sustento sanitario y epidemiológico.

\subsection{Una asesoría científica desplazada y relegada}

Las debilidades estructurales de la asesoría científica en Guatemala devienen de la falta de fuentes de financiamiento, de los atrasos en la oferta y en la demanda de conocimiento, de la poca valoración de los aportes científicos existentes, así como de la ausencia de una institucionalidad más amplia e integrada del sistema de ciencia y tecnología como sucede en otros países de América Latina. No obstante, como se observó en la naturaleza y en el contenido de las decisiones de política pública tanto sanitaria como laboral, fue una decisión política del presidente el desplazamiento y el relegamiento de los asesores científicos con los que el gobierno central contaba y que tenían la capacidad necesaria ${ }^{22}$ para ser útiles, pertinentes y rigurosos para gestionar de una mejor manera las consecuencias del Covid-19.

Esa decisión en favorecimiento de las cámaras empresariales en clave exclusivamente económica conllevó a la indiferencia del papel que podía desempeñar el $\operatorname{INE}^{23}$ y la SENACYT, así como de las recomendaciones de los expertos en salud pública como la AGEI, el MSPAS y la Coprecovid, siendo la última la que estuvo a cargo de la consejería científica entre junio y diciembre de 2020. De hecho, la decisión de que funcionara únicamente durante 6 meses cuando la pandemia iba a seguir existiendo, sin que se realizara un traslado de conocimientos y capacidades, y sin que el Semáforo Epidemiológico estuviese siendo respetado y utilizado para definir la escalada o desescalada de restricciones reafirma que la Coprecovid fue traída para justificar el regreso forzado a la normalidad, pero, sobre todo, demuestra el poco valor que el gobierno central y el presidente Giammattei le dieron a la asesoría científica durante la gestión de la pandemia.

22 Aunque no tuvieran los mejores recursos y los mejores antecedentes en algunos casos.

23 Durante 2020 le redujeron de su presupuesto anual 20 millones de quetzales debido a que no podrían realizar sus encuestas nominales de manera presencial, quedando así en una situación de vulnerabilidad institucional y ya sobre la marcha sin posibilidad de realizar mediciones del impacto del Covid-19 en las áreas de su competencia. No obstante, cabe señalar que no defendieron la realización de las encuestas por otros métodos, como el telefónico, lo cual podría haber asegurado el mantenimiento de su presupuesto. 


\section{Conclusiones}

El gobierno central adoptó rápidamente una serie de medidas de confinamiento y distanciamiento social de carácter parcial tomando como referencia la experiencia internacional y el consejo científico de la AGEI, lo cual permitió contener la propagación explosiva de los contagios alrededor de dos meses.

El gobierno central cedió a las presiones públicas y privadas del CACIF, relegó la asesoría científica y comenzó a tomar decisiones contradictorias cada dos semanas, quedando atrapado entre la demanda de la comunidad científica y de la sociedad civil por privilegiar la salud pública y la orden de la cúpula empresarial exigiendo la apertura de la economía. El hecho de no agotar sin retrocesos un plan de contención y respuesta de orden científico y epidemiológico tuvo como desenlace que la desesperación y la desconfianza a las medidas gubernamentales fueran ganando terreno, provocando que en la práctica se terminara permitiendo el funcionamiento de la mayoría de las actividades económicas y, posteriormente, de las actividades públicas y privadas.

El CACIF tomó pleno control de la política sanitaria y laboral después de las medidas de confinamiento parcial que duraron entre el 15 de marzo y el 12 de abril, imponiéndose incluso sobre la asesoría científica de la Coprecovid, cuyo establecimiento tenía como supuesto propósito priorizar los criterios técnicos y científicos en la gestión de la pandemia.

La política sanitaria careció de alianzas interinstitucionales e intersectoriales para su implementación, monitoreo, evaluación y mejoría. Las municipalidades se convirtieron en gestoras sin recursos y sin coordinación en el manejo de datos; y las iniciativas ciudadanas, periodísticas y universitarias fueron aisladas aun cuando estaban realizando una labor estupenda en llenar los vacíos de información y análisis que generaba el gobierno central.

La idea de control sobre la sociedad con cariz autoritario desde el gobierno central se impuso sobre la mitigación del virus y la distribución estratégica de las personas en los centros de trabajo, en los parques industriales y en los espacios públicos. Revelando a su vez la carencia de voluntad democrática y la desvalorización de la asesoría científica para la toma de decisiones en el país. 


\section{Bibliografía}

Castellanos, P. (2020). Carta abierta a Secretaría de Ciencia y Tecnología (SENACYT). Obtenido de Plaza Pública: https://www.plazapublica.com.gt/sites/default/files/carta_abierta. pdf

Chang, J. D. (13 de mayo de 2020). La «cura al coronavirus» desnuda las deficiencias de la Senacyt. Plaza Pública. Recuperado el 18 de noviembre de 2020, de https://www. plazapublica.com.gt/content/la-cura-al-coronavirus-desnuda-las-deficiencias-de-lasenacyt

Chávez, Ó. (23 de noviembre de 2020). El papel de la Coprecovid en la gestión de la pandemia en Guatemala (L. G.Velásquez Pérez, entrevistador)

García, J. (16 de abril de 2020). Patzún: el miedo al virus acaba con la comida. Nómada. Recuperado el 18 de Mayo de 2021, de https://nomada.gt/pais/actualidad/patzun-elmiedo-al-virus-acaba-con-la-comida/

Gutiérrez Valdizán, A. (10 de abril de 2020). Lo que importa son las vidas humanas y no la economía. Agencia Ocote. Recuperado el 25 de noviembre de 2020, de https:// www.agenciaocote.com/blog/2020/04/10/arathoon-son-las-vidas-humanas-y-no-laeconomia-lo-que-importa/

Inspección General de Trabajo (julio de 2020). Número de denuncias ingresadas a la Inspección General de Trabajo por la emergencia del Covid-19. Guatemala.

Johns Hopkins University (29 de noviembre de 2020). COVID-19 Dashboard by the Center for Systems Science and Engineering (CSSE) at Johns Hopkins University (JHU). Obtenido de Coronavirus Resource Center: https://coronavirus.jhu.edu/map.html

Marroquín, R. (21 de junio de 2020). COVID19. Todas las cadenas del Presidente. Plaza Pública. Recuperado el 26 de noviembre de 2020, de https://www.plazapublica.com. $\mathrm{gt} /$ content/covid19-todas-las-cadenas-del-presidente

Mazariegos Rivas, A. (24 de abril de 2020). Giammattei se reunió con Asociación de Infectólogos, pero la decisión de reducir el toque de queda no se tomó en conjunto. Agencia Ocote. Recuperado el 24 de noviembre de 2020, de https://www.agenciaocote. com/blog/2020/04/24/giammattei-se-reunio-con-asociacion-de-infectologos-perola-decision-de-reducir-el-toque-de-queda-no-se-tomo-en-conjunto/

Ministerio de Economía (2020). Informe de autorización de empresas. Guatemala.

Ministerio de Salud Pública y Asistencia Social (2020). Situación de COVID-19 en Guatemala. Recuperado el 19 de mayo de 2021, de Ministerio de Salud Pública y Asistencia Social: https://tablerocovid.mspas.gob.gt/ 
Ortiz, G. (15 de mayo de 2020).Asturias apela a convocar a los mejores científicos, economistas y graduar médicos. La Hora. Recuperado el 11 de noviembre de 2020, de https:// lahora.gt/asturias-apela-a-convocar-a-los-mejores-cientificos-economistas-y-graduarmedicos/

Prensa Comunitaria (5 de mayo de 2020). Patzún, municipio con el primer caso "comunitario" de COVID-19 en Guatemala. Un relato sobre el cordón sanitario y la transformación de la vida cotidiana. Prensa Comunitaria. Recuperado el 18 de mayo de 2021 de https:// prensacomunitar.medium.com/patz\%C3\%BAn-municipio-con-el-primer-casocomunitario-de-covid-19-en-guatemala-1ac535b60028

Stein, et al. (2006). "La política de las políticas públicas. Progreso económico y social en América Latina. Informe 2006" Banco Interamericano de Desarrollo, Washington,

UNESCO (2017). Relevantamiento de la Investigación y la Innovación de la República de Guatemala. Paris: UNESCO. Obtenido de https://unesdoc.unesco.org/ark:/48223/pf0000248067

Valdés, M. \& Naveda, E. (18 de diciembre de 2018). La élite económica de Guatemala, entre las más acaparadoras de América Latina. Plaza Pública. Recuperado el 28 de noviembre de 2020, de https://www.plazapublica.com.gt/content/la-elite-economica-deguatemala-entre-las-mas-acaparadoras-de-america-latina

Velásquez Pérez, L. G. (abril de 2020). Elementos para el análisis del comportamiento del covid-19 en Guatemala. Revista de Análisis de la Realidad Nacional(182), 84-104. Obtenido de http://ipn.usac.edu.gt/wp-content/uploads/2020/04/IPN-RD-182.pdf

Enviado: 17 de febrero de 2021

Aceptado: 11 de junio de 2021 
